$12-2012$

\title{
Variation in fast-start performance within a population of polyphenic bluegill (Lepomis macrochirus)
}

\author{
Shannon Page Gerry \\ Fairfield University, sgerry@fairfield.edu
}
A. Robbins
D. J. Ellerby

Follow this and additional works at: https://digitalcommons.fairfield.edu/biology-facultypubs Copyright 2012 University of Chicago Press

Archived (with 12-month embargo) with permission from copyright holder.

Available at http://www.jstor.org/stable/10.1086/667593

\section{Peer Reviewed}

\section{Repository Citation}

Gerry, Shannon Page; Robbins, A.; and Ellerby, D. J., "Variation in fast-start performance within a population of polyphenic bluegill (Lepomis macrochirus)" (2012). Biology Faculty Publications. 24. https://digitalcommons.fairfield.edu/biology-facultypubs/24

\section{Published Citation}

Gerry, S.P., *Robbins, A. and Ellerby, D.J. November/December 2012. Variation in fast-start performance within a population of polyphenic bluegill (Lepomis macrochirus). Physiological and Biochemical Zoology, 85(6), pp. 697-703.

This item has been accepted for inclusion in DigitalCommons@Fairfield by an authorized administrator of DigitalCommons@Fairfield. It is brought to you by DigitalCommons@Fairfield with permission from the rightsholder(s) and is protected by copyright and/or related rights. You are free to use this item in any way that is permitted by the copyright and related rights legislation that applies to your use. For other uses, you need to obtain permission from the rights-holder(s) directly, unless additional rights are indicated by a Creative Commons license in the record and/or on the work itself. For more information, please contact digitalcommons@fairfield.edu. 


\section{Variation in Fast-Start Performance within a Population of Polyphenic Bluegill (Lepomis macrochirus)*}

\author{
Shannon P. Gerry ${ }^{1,2, \dagger}$ \\ Allison Robbins ${ }^{1}$ \\ David J. Ellerby ${ }^{1}$ \\ ${ }^{1}$ Department of Biological Sciences, Wellesley College, \\ Wellesley, Massachusetts 02481; ${ }^{2}$ Department of Biology, \\ Fairfield University, Fairfield, Connecticut 06824
}

Accepted 6/28/2012; Electronically Published 8/15/2012

\begin{abstract}
Bluegill sunfish Lepomis macrochirus exhibit intraspecific variation in their morphology and swimming performance based on habitat. The pelagic form has a relatively streamlined, fusiform body shape associated with greater steady-state swimming speed and energy economy. In contrast, littoral bluegill have deeper bodies with fins located farther from their center of mass to enhance maneuverability among littoral vegetation. Deeper body shapes have been associated with increased faststart performance to escape predators or capture prey. We hypothesized that littoral bluegill, which have a deeper body shape, would exhibit greater fast-start performance than pelagic bluegill. A total of 29 bluegill (16 littoral, 13 pelagic) were caught by hook and line, and their fast-start performance was analyzed from high-speed video recordings. Body shape appears to be a poor predictor of fast-start performance. Contrary to our expectations, pelagic bluegill had a significantly higher peak velocity, peak acceleration, and angular velocity compared to littoral bluegill. Pelagic bluegill living among larger predators and foraging on mobile prey may be exposed to selection pressures that favor increased fast-start performance. Integrated studies of internal morphology and physiology are needed to fully understand the relationship between morphology and performance in this population.
\end{abstract}

\section{Introduction}

Many fish species have polyphenic populations in which morphological divergence has been linked to diversifying selection

\footnotetext{
* This paper was submitted in response to a call for papers for a Focused Issue on "Intraspecific Variation in Physiology and Behavior."

†Corresponding author; e-mail: sgerry@fairfield.edu.
}

Physiological and Biochemical Zoology 85(6):694-703. 2012. (C) 2012 by The University of Chicago. All rights reserved. 1522-2152/2012/8506-1162\$15.00. DOI: $10.1086 / 667593$ constrained by performance trade-offs (Schluter 1994; Robinson et al. 1996; Robinson 2000; Svänback and Eklöv 2003; Bolnick and Lau 2008). Freshwater populations consistently diverge into littoral and pelagic ecomorphs that differ in foraging behavior, diet, and external morphology (Mittelbach 1981; Ehlinger and Wilson 1988; Ehlinger 1990; Schluter 1994; Yonekura et al. 2002; Jastrebski and Robinson 2004; Parsons and Robinson 2006, 2007; Bolnick and Lau 2008; Bhagat et al. 2011; Gerry et al. 2011). Morphological differences between littoral and pelagic fish have been linked to potential performance differences in feeding or locomotion, largely on the basis of broader interspecific comparisons. Littoral forms are typically deeper bodied and have larger fins that are located relatively farther from their body center of mass (COM), which are features that are associated with enhanced performance during unsteady swimming behaviors, include turning maneuvers and fast-starts to avoid predators or capture prey (Webb 1984; Walker 1997; Blake 2004; Langerhans and Reznick 2010; Gerry et al. 2011; Ellerby and Gerry 2011). Pelagic forms typically have more fusiform body shapes that likely incur less drag, which facilitates sustained swimming at low energetic cost (Webb 1984; Walker 1997; Domenici 2003; Gerry et al. 2011; Ellerby and Gerry 2011). Phenotypic features associated with steady, economical swimming appear incompatible with effective unsteady swimming and vice versa, which may create a trade-off between sustained and unsteady swimming performance between fish from different habitats. These potential trade-offs within fish populations have largely been inferred from external morphology; however, recent empirical evidence has supported this view. Within a polyphenic bluegill sunfish population, a trade-off is present between energy economy and speed during steady swimming and maneuverability around obstacles (Ellerby and Gerry 2011).

Maneuverability represents one aspect of a wide repertoire of unsteady swimming behaviors that encompass both the ability of a fish to traverse a complex physical environment and fast-starts, which are rapid accelerations of the body to evade predators or capture prey. Fast-starts are an important component of organismal fitness, because fish that exhibit faster starts are better able to evade predators (Walker et al. 2005; Blob et al. 2010). Fast-start performance has been coupled with particular aspects of body shape. An increased depth along the length of the body is associated with the effective transfer of momentum to the water during the high-amplitude bending of the body axis that is characteristic of fast-starts (Weihs 1973; Webb 1978), and selection pressures imposed by predation may favor fish with deeper bodies (Domenici et al. 2008; Langerhans 2009; Blob et al. 2010). In bluegill sunfish, the deep body profile is augmented by a deep caudal and large dorsal and anal fins 
that contribute to thrust production (Tytell and Lauder 2008). Polyphenic sunfish populations in which body and fin shape vary in respect to habitat provide an opportunity to investigate the links between body shape and fast-start performance without the effects of phylogenetic distance that complicate interspecific comparisons of morphology and performance (Garland et al. 2005).

We quantified fast-start performance in a population of polyphenic bluegill sunfish Lepomis macrochirus Mitchill that are known to differ in their external morphology (Gerry et al. 2011), steady swimming performance, energy economy, and maneuverability (Ellerby and Gerry 2011). On the basis that littoral bluegill have deeper body profiles than their pelagic counterparts (fig. 1; Gerry et al. 2011), we hypothesized that littoral fish would exhibit higher velocities and accelerations during fast-starts and that a steady-versus-unsteady swimming performance trade-off would exist in which the enhanced steady swimming performance of the pelagic form would be associated with reduced fast-start performance.

\section{Material and Methods}

Bluegill sunfish Lepomis macrochirus were caught by hook and line in Lake Waban, Massachusetts, from June through July 2011. Pelagic fish were caught in open, macrophyte-free water greater than $5 \mathrm{~m}$ in depth. Littoral fish were caught at water depths of less than $1 \mathrm{~m}$ and in the presence of macrophyte beds. Fish were transferred to the laboratory for overnight acclimation before performance testing and morphological measurements. Experiments were performed at $22^{\circ} \mathrm{C}$. This temperature was similar to epilimnion temperatures in the lake during the collection period. Mean masses $( \pm$ SEM) of the 16 littoral ( 9 male, 7 female) and 13 pelagic ( 7 male, 6 female) fish were $0.115 \pm 0.008$ and $0.110 \pm 0.007 \mathrm{~kg}$, respectively, and mean total lengths $( \pm$ SEM $)$ were $0.179 \pm 0.004$ and $0.183 \pm$ $0.004 \mathrm{~m}$, respectively. No significant differences in body length ( $t$-test, $t=0.76, P>0.05$ ) or mass ( $t$-test, $t=0.44, P>0.05$ ) were detected between groups. All research was approved by the Wellesley College Institutional Animal Care and Use Committee.

Individual fish were transferred to a $45 \times 90-\mathrm{cm}$ tank with a water depth of $15 \mathrm{~cm}$. Fast-starts were recorded from above using an AOS X-PRI camera (AOS Technologies, Baden Daettwil, Switzerland) at a frame rate of $500 \mathrm{~Hz}$ and resolution of $1,024 \times 800$ pixels $(1$ pixel $=0.6 \mathrm{~mm})$. Fish were startled by tapping the bottom of the tank with a length of PVC pipe. To minimize performance variability due to inconsistency of the stimulus, the tank was always tapped directly in front of the snout of the fish.

Several replicates may be required to arrive at reasonable estimates of maximal performance (Adolph and Pickering 2008); therefore, fish were tested in multiple trials, and the best performances were compiled for analysis. Preliminary analyses based on up to 10 consecutive trials, with 3 min rest between trials, showed that 5 replicates per individual were sufficient to yield performance measures that were asymptotically approaching a maximal value without producing a decrease in performance over time as a result of fatigue or familiarity with the stimulus.

Video sequences were downloaded to a personal computer using AOS Digital Imaging software. The COM of bluegill sunfish is located approximately $40 \%$ of total body length from the snout when the fish is in a straight position (Tytell and
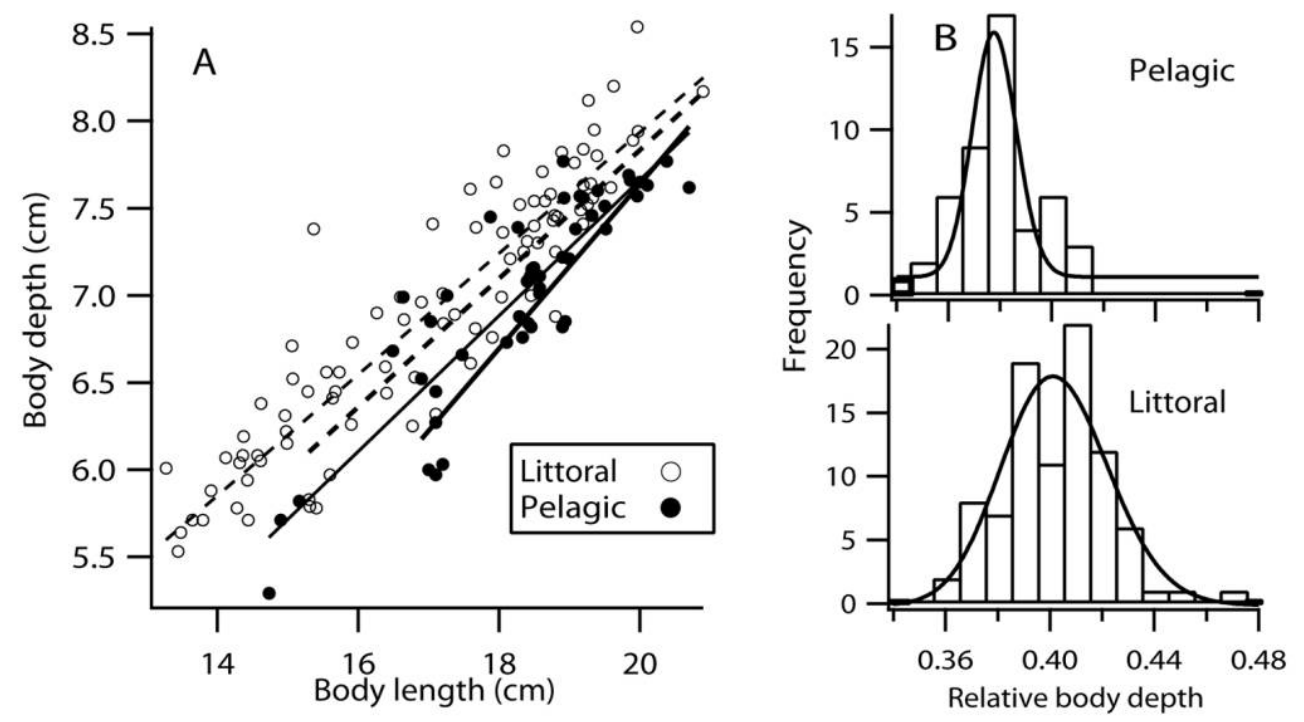

Figure 1. A, Relationship between body depth and length for littoral (open circles) and pelagic (filled circles) bluegill sunfish. Data are fitted with linear regressions. Littoral and pelagic data sets are fitted with dashed and solid lines, respectively. Thicker lines are fitted to data points for fish from this study only. B, Frequency distribution of relative body depths (as a proportion of body length) of pelagic and littoral fish. Lines show lognormal curves fitted to the distributions. Data include fish from this study and from Gerry et al. (2011). 
Lauder 2008; Gerry et al. 2011). This location on the midline and the snout of each fish were tracked using Image J. Although typically taken as an indicator of COM position during faststarts for tracking purposes (Webb 1978; Domenici and Blake 1997), the true COM does shift from the straight body COM location during body bending (Wakeling 2006). Position data were smoothed using a smoothing spline interpolation in the application Igor Pro (ver. 6.2, Wavemetrics, Lake Oswego, OR). This method is similar to the cubic spline algorithm recommended by Walker (1998) for calculating velocities and accelerations from position data. The level of smoothing is dictated by the standard deviation of the data. Smoothed COM position data were differentiated to obtain COM velocity, and velocity was differentiated to obtain COM acceleration. The COM and snout position data were used to calculate the heading of the fish. The body axis between the COM and snout is inflexible, and the vector between these two points indicates fish heading. The heading angle of the fish relative to the $Y$-direction $\left(\theta^{\circ}\right)$ was calculated as $\theta^{\circ}=\tan ^{-1}\left(d_{x} / d_{y}\right)(360 / 2 \pi)$, where $d_{x}$ and $d_{y}$ are the distances between the COM and snout in the $X$ and $Y$ directions. Angle data were smoothed using a spline interpolation, as for the position data, and were differentiated to give a turning rate in degrees per second. Fast-starts are typically divided into two kinematic phases (reviewed in Domenici and Blake 1997; Wakeling 2006). Phase 1 consists of the initial Cbend, and phase 2 consists of the subsequent reverse tail stroke. These can be defined on the basis of snout angular velocity. Phase 1 consists of an initial velocity peak, decreasing transiently to 0 at the end of phase 1 before a second angular velocity peak of opposite sign associated with phase 2, again decreasing to 0 at the completion of this phase (Domenici and Blake 1997; Tytell and Lauder 2008). We report escape angle, the total angle turned by the fish during phases 1 and 2, peak COM velocity $\left(\mathrm{m} \mathrm{s}^{-1}\right)$, peak COM acceleration $\left(\mathrm{m} \mathrm{s}^{-2}\right)$, peak angular velocity (degrees $\mathrm{s}^{-1}$ ), and the total combined distance moved by the COM during phases 1 and $2(\mathrm{~m})$.

After the experimental trials, each fish was lightly anesthetized using tricaine methane sulphonate (MS222, $75 \mathrm{mg} \mathrm{L}^{-1}$, buffered with $\mathrm{NaOH}$ ), weighed, and photographed (using a Canon Powershot S51S mounted on a tripod) in left lateral and frontal views for morphometric analysis. Morphological variables were measured using Image J, following Gerry et al. (2011), and included total length, body depth, body width, body lateral area, and areas of the spiny dorsal, soft dorsal, anal, and caudal fins. These were chosen because of their potential functional association with fast-start performance (Weihs 1973; Tytell and Lauder 2008). For additional analyses, body depth and width were expressed as proportions of body length, and areas were expressed relative to body mass to the two-thirds power.

\section{Statistical Analyses}

Statistical analyses, with the exception of the escape angle data, were performed using SPSS, version 18. Data were tested for normality using a Kolmogorov-Smirnov test $(P<0.05)$ and Levene's equality of error variances test $(P<0.05)$. Data distri- butions did not differ significantly from normality, and no differences in variance were detected between samples. ANCOVA was used to test for differences in body depth between groups (body length as a covariate) using the general linear model function in SPSS. If a performance variable correlated with body size (angular velocity correlated with body length, Pearson, $P<0.05)$, ANCOVA with the body length as a covariate and habitat type as a fixed factor was used to test for performance differences between groups. If there was no correlation between performance and size (COM acceleration, COM velocity, and distance moved), then ANOVA with habitat type as a fixed factor was used to test for performance differences. No performance differences were detected with respect to sex, so this was not included as a factor in the general linear models, although this may be associated with a lack of statistical power concerning the relative sample sizes of males versus females within each habitat group.

Principal components analysis (PCA) was used to extract a reduced number of components that described the variation in the morphological data. The spiny dorsal fin area, frontal area, and body width variables did not meet the Kaiser-MeyerOlkin (KMO) requirements for sampling adequacy (scores $<0.5$ ) and were removed from the analysis, and we retained the relative areas of the body in lateral view and the anal, soft dorsal, and caudal fins and the relative body depth. These met the KMO requirements, and Bartlett's test of sphericity $(P=$ 0.002 ) further indicated that the data were suitable for factor analysis. Kaiser's rule was applied, retaining factors with eigenvalues greater than 1, confirmed by inspection of the scree plot. Varimax orthogonal rotation was applied to the component matrix. Although necessarily producing uncorrelated components and simplifying data interpretation, imposition of orthogonality can distort the component scores (Grice 2001). To check for this, an oblique rotation was also applied, but a similar matrix structure was obtained.

To account for the use of multiple comparisons, the experiment-wise error rate was adjusted using a sequentially rejective multiple-test procedure applying Ryan's $Q$ (Ryan 1960). Cohen's $d$ (Cohen 1988) was calculated as an indicator of effect size, $d=\left(m_{1}-m_{\mathrm{p}}\right) / \sigma_{\text {pooled }}$ where $m_{1}$ and $m_{\mathrm{p}}$ were the mean values for the littoral and pelagic groups, respectively, and $\sigma_{\text {pooled }}$ was the root mean square of their standard deviations. The standard deviation of Cohen's $d$, an indicator of the robustness of the effect size estimate, was calculated as

$$
\sqrt{\left[\frac{n_{1}+n_{\mathrm{p}}}{n_{1} n_{\mathrm{p}}}+\frac{d^{2}}{2\left(n_{1}+n_{\mathrm{p}}-2\right)}\right]\left(\frac{n_{1}+n_{\mathrm{p}}}{n_{1}+n_{\mathrm{p}}-2}\right)},
$$

where $n_{1}$ and $n_{\mathrm{p}}$ were the numbers of littoral and pelagic fish, respectively (Cooper and Hedges 1994). Effect sizes are classified as small $(0.2 \leq d<0.5)$, medium $(0.5 \leq d<0.8)$, and large $(d \geq 0.8$; Cohen 1988).

Escape angle data were analyzed using a circular statistics package (Oriana, ver. 3.21, Kovach Computing Services, Pentraeth). Multiple pairwise comparisons based on the MardiaWatson-Wheeler test were used to test for interindividual var- 

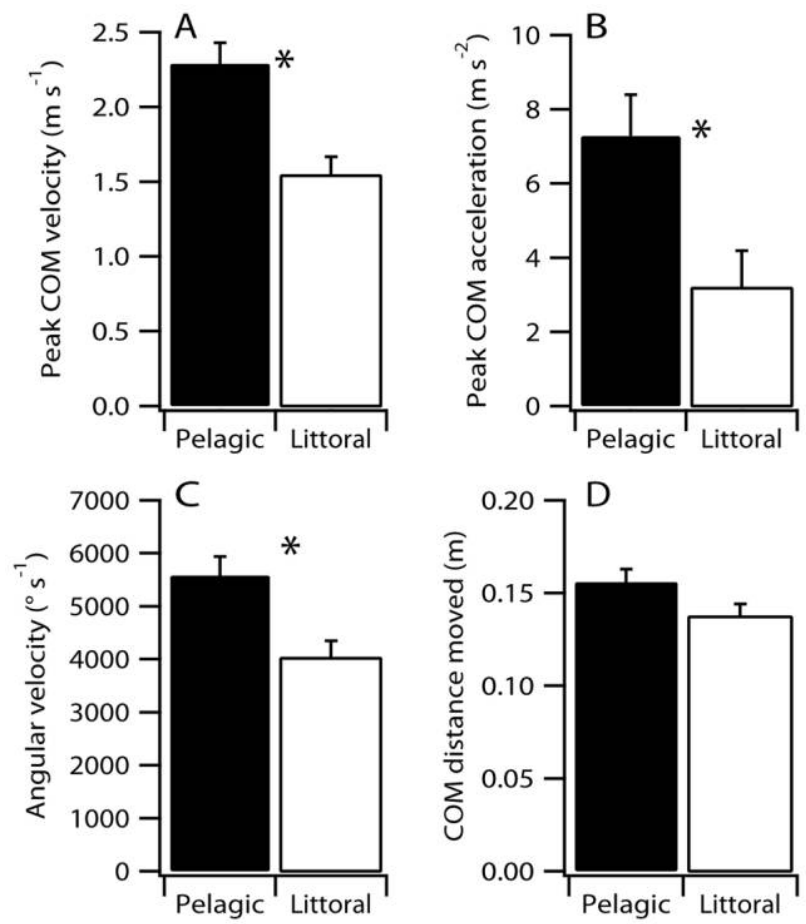

Figure 2. Comparison of fast-start performance variables, including $(A)$ peak center of mass $(\mathrm{COM})$ velocity, $(B)$ peak COM acceleration, $(C)$ angular velocity, and $(D)$ COM distance moved. Filled bars show pelagic $(N=13)$ and open bars show littoral $(N=16)$ bluegill. Asterisks indicate statistical significance using a sequentially rejective multiple test procedure applying Ryan's $Q$.

iation in escape angle. This is a nonparametric test for differences between samples of circularly distributed data. None were detected, and the angle data within the littoral and pelagic groups were pooled for additional analyses. A binomial test was used to determine whether left : right directional preferences differed from a 1:1 ratio. No directional preference was detected in either group, and data from left and right turns were pooled for additional analysis. Pooled trajectory distributions for littoral and pelagic fish were compared with both uniform and circular normal distributions using Watson's $U^{2}$ test. Comparisons between the littoral and pelagic angle distributions were made using a Mardia-Watson-Wheeler test. Inspection of the trajectory distributions suggested the presence of multiple peaks. A two-step cluster analysis procedure (PASW, ver. 18.0, IBM, New York) was used to determine whether the patterns were similar in both habitats. The clustering algorithm identifies normally distributed clusters within the overall frequency distribution. The number of clusters is not assumed a priori. A model is chosen on the basis of an information criterion that balances model fit and model complexity, the aim being to maximize closeness of fit while limiting the number of parameters in the model. A number of such criteria are available. We applied the Schwarz Information Criterion (also known as the Bayesian Information Criterion; Schwarz 1978). This is conservative in terms of imposing a relatively large penalty for increased model complexity and minimizes the potential for overfitting, which is the selection of excessively complex models (Sneek 1984; Koehler and Murphree 1988).

\section{Results}

Bluegill sunfish show intraspecific variation in fast-start performance. Pelagic individuals had a significantly greater peak COM velocity (ANOVA, $F_{1,28}=15.8, P<0.001$, Cohen's $d=$ $-1.5 \pm 0.4$; fig. $2 A$ ) and peak COM acceleration (ANOVA, $F_{1,28}=7.4, P=0.01$, Cohen's $d=-1.0 \pm 0.4$; fig. $2 B$ ). Pelagic bluegill also had a greater turning rate than littoral bluegill (ANCOVA, $F_{1,28}=11.0, P=0.003$, Cohen's $d=-0.9 \pm 0.4$; fig. $2 C$ ). No difference was detected in the distance moved between the pelagic and littoral groups (ANCOVA, $F_{1,28}=$ 3.38, $P=0.07$, Cohen's $d=-0.7 \pm 0.4$; fig. $2 D)$, although the magnitude of Cohen's $d$ suggests that there may be an effect associated with habitat type.

There were significant differences in body depth between littoral and pelagic fish for a collated data set incorporating morphological data from earlier studies (Gerry et al. 2011) and for the fish from this study (fig. 1; ANCOVA, $F_{1,111}=29.1$, $P<0.001$, all data; ANCOVA, $F_{1,28}=13.0, P<0.001$, fish from this study). Relative body depth was weakly associated with peak swimming velocity in both groups of fish (fig. $3 A$; Pearson's $r>0.3$ ) and significantly correlated with peak acceleration in pelagic bluegill (fig. $3 B$; Pearson's $r>0.5, P<0.05$ ). Body depth was not associated with peak angular velocity (fig. 

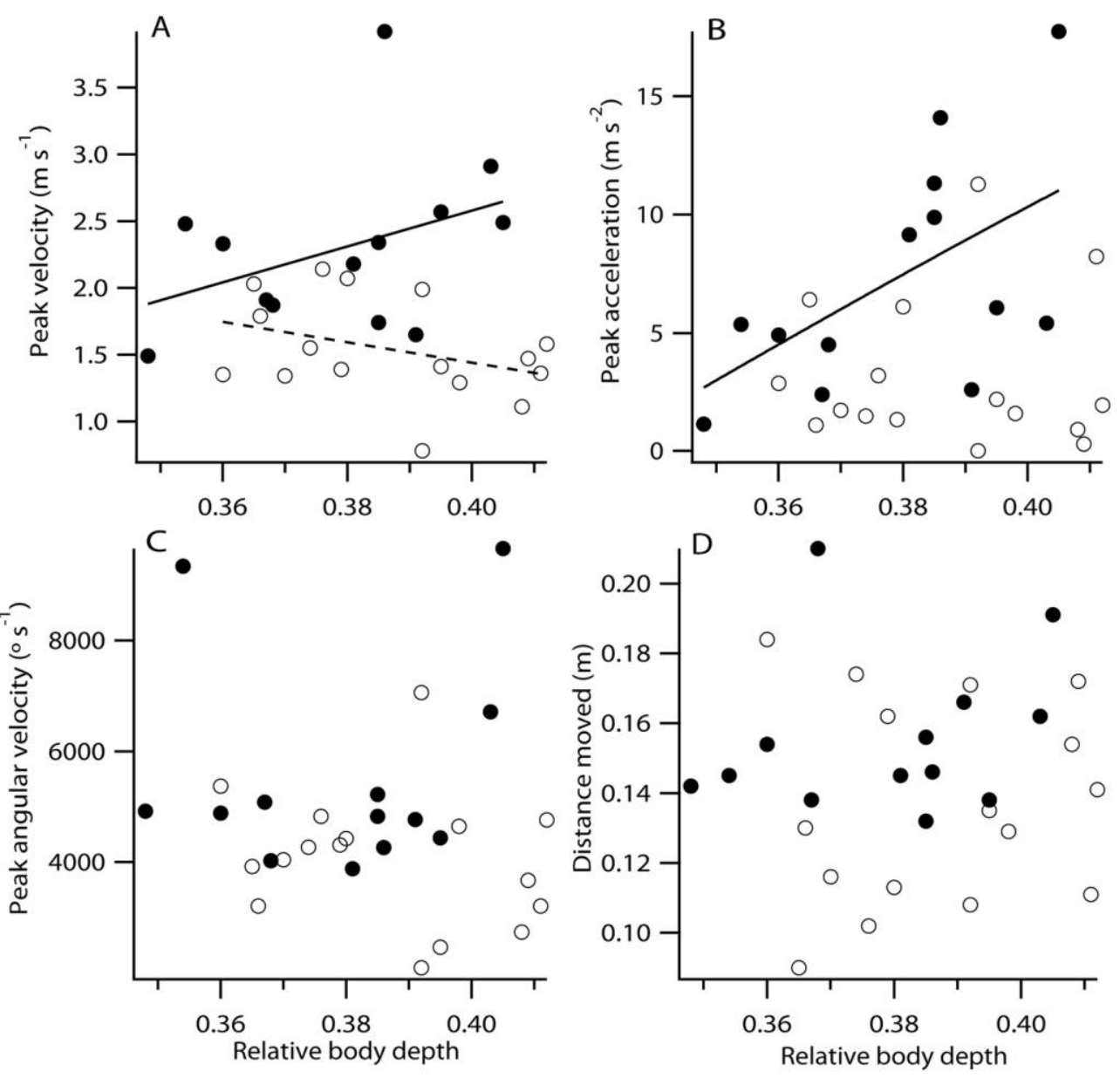

Figure 3. Relationship between relative body depth to $(A)$ peak center of mass $(\mathrm{COM})$ velocity, $(B)$ peak COM acceleration, $(C)$ peak angular velocity, and $(D)$ COM distance moved. Filled circles show pelagic $(N=13)$ and open circles show littoral $(N=16)$ bluegill. Lines represent Pearson product-moment correlation coefficients of 0.3 or greater, which indicates medium to large effect sizes (Cohen 1988).

3C) or distance moved (fig. 3D). PCA identified two components that describe $66 \%$ of the variation in the morphological data from this study. Principal component 1 (PC1) accounted for $41.9 \%$ of the variation, and fin areas all loaded heavily on this component (table 1). PC2 accounted for an additional $24.4 \%$ of the variation. Body area and body depth crossloaded on this component (table 1). A high score for PC1 is associated with larger relative size of the fins that are associated with thrust production during fast-starts in bluegill (Tytell and Lauder 2008). A high score for PC2 is associated with a deeper body shape and lower relative lateral body area. This is counterintuitive, because all other things being equal, increased body depth in relation to length should be associated with increased lateral area. In this case, area is expressed relative to mass to the two-thirds power, not as a function of length, so body shape and area are not necessarily coupled. The component scores for individual fish are plotted in figure 4. The distribution of component scores for the littoral and pelagic fish confirm previous observations of differences in body shape, with littoral fish being deeper bodied overall (higher scores on PC2). Pelagic fish score higher on $\mathrm{PC1}$, which indicates greater relative fin areas. Correlations between performance and the PC scores for both components are shown in table 2. There was a strong negative relationship between peak angular velocity and PC1 in both the pelagic and littoral fish. Acceleration had a strong

Table 1: Component scores resulting from reduction of the morphological data by principal component (PC) analysis

\begin{tabular}{lcc}
\hline $\begin{array}{l}\text { Morphological } \\
\text { variable }\end{array}$ & PC1, fin area & PC2, body shape \\
\hline Caudal fin area & $\mathbf{. 7 2}$ & -.05 \\
Soft dorsal fin area & $\mathbf{. 8 3}$ & -.01 \\
Anal fin area & $\mathbf{. 8 2}$ & .39 \\
Relative body depth & .15 & $\mathbf{. 8 0}$ \\
Lateral body area & .05 &.$- \mathbf{8 0}$ \\
\hline
\end{tabular}

Note. A varimax orthogonal rotation was applied to the scores. The highest scores for each component are highlighted in bold. 


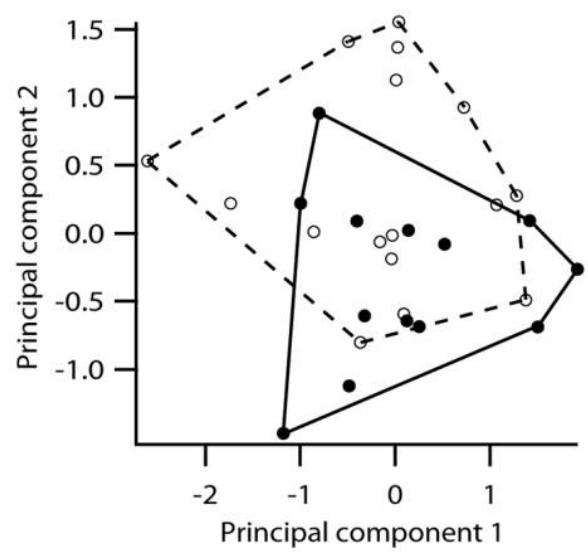

Figure 4. Plot of component scores generated by principal components analysis of the morphological data. High scores for component 1 were associated with increasing relative area of the caudal, anal, and soft dorsal fins. High scores for component 2 were associated with increasing relative body depth and decreasing relative lateral body area. Data for littoral fish are shown by open symbols bounded by a dashed line, and data for pelagic fish are shown by filled symbols bounded by a solid line.

positive association with $\mathrm{PC} 2$ in the pelagic fish but not in the littoral fish.

The proportion of observed left versus right turns in response to the stimulus did not differ significantly from a $1: 1$ ratio for either littoral (Binomial test, observed proportions 0.45 right, 0.55 left, $P=0.526$ ) or pelagic (Binomial test, observed proportions 0.39 right, 0.61 left, $P=0.117$ ) fish. The escape angles for each group were neither uniformly nor normally distributed (Watson's $U^{2}$-test, $P<0.05$ ). Two clusters were identified within the frequency distribution for fish from both habitats (fig. 5). All clusters had a circular normal distribution (Watson's $U^{2}$-test, $P>0.05$ ). No significant differences were detected in the mean values of equivalent clusters across groups (Mardia-Watson-Wheeler, $P>0.05$ ).

\section{Discussion}

Fast-start performance has been compared between species (Webb 1978) and across populations within species (Taylor and McPhail 1985, 1986; Ghalambor et al. 2004; Domenici et al. 2008); however, this is, to our knowledge, the first study to examine variation between habitat-specific forms within a single population. The majority of these studies acknowledge a trade-off between unsteady versus steady swimming correlated with body morphology. Fishes that exhibit superior prolonged swimming behaviors have fusiform, streamlined bodies to reduce drag (Taylor and McPhail 1985, 1986; Blob et al. 2010; Langerhans and Reznick 2010). A deeper body shape and large lateral area should enable effective transfer of momentum to the water during the rapid body bending generated during the fast-start (Weihs 1973; Webb 1978; Tytell and Lauder 2008), and empirical studies have found improved fast-start perfor- mance or evasion of predators in deeper-bodied fish (Domenici et al. 2008; Langerhans 2009; Blob et al. 2010).

Our findings concerning bluegill fast-start performance are contrary to our initial predictions based on body shape. Littoral bluegill have deeper bodies than pelagic bluegill (fig. 1; Ellerby and Gerry 2011; Gerry et al. 2011), yet this characteristic does not translate into faster starts compared with those of the more fusiform, pelagic bluegill (fig. 2). Although trade-offs in performance between steady and unsteady swimming are present in this population, they apply only to certain aspects of these behavioral categories. The pelagic form is effective and economical at steady swimming and less maneuverable than the littoral form (Ellerby and Gerry 2011), yet it is more effective at accelerating during fast-starts (this study).

The relationships between body and fin shape, as summarized by principal component scores, and fast-start performance are generally weak in polyphenic bluegill (table 2). The main exception is the strong negative association between PC1 and peak angular velocity in both groups of fish (table 2). PC1 is associated with fin area, specifically with that of the caudal, anal, and soft dorsal fins. These all contribute to momentum transfer to the water during the fast-start (Tytell and Lauder 2008). By effectively increasing the lateral surface area for momentum transfer, large fins may limit the rate of body rotation. PC2, a descriptor of body shape and lateral body area, is positively associated with COM acceleration, but only in pelagic fish (table 2). Higher PC2 scores are associated with a deeper body shape. This fits with expectations based on previous work, but it applies only to one form type, not across the entire population. This finding has potential implications for studies of locomotor performance in many species, because habitatrelated variation in performance and/or phenotype, if unaccounted for, could obscure or distort phenotype-function relationships.

Although earlier work has focused on the potential influences of body shape on fast-start performance (Weihs 1973; Webb 1984), in a complex behavior that is influenced by a wide range of both external and internal morphological and physiological factors, there are many ways in which performance can be decoupled from external morphology (table 1). For example, the morphology and/or contractile properties of the myotomal muscle that acts as the power source also determine performance, and when deeper body shapes have been associated with increased fast-start performance, differences in myotomal muscle mass have also been demonstrated (Webb 1978; Domenici et al. 2008). This study and related work on morphological and performance variation within and between habitats in the study population show that this is a promising system for examining relationships between morphophysiological factors and performance. However, precise resolution of the interrelationships between phenotype and function will require detailed, highly integrated measures of external and internal morphology; physiological factors, such as muscle contractile properties; and multiple aspects of steady and unsteady swimming performance made concurrently in the same group of individuals. 
Table 2: Pearson product-moment correlation (PPMC) coefficients for relationships between fast-start performance and body shape as summarized by principal component (PC) analysis

\begin{tabular}{lrrrrrr}
\hline & \multicolumn{2}{c}{ PC1, thrust } & & \multicolumn{2}{c}{ PC2, body shape } \\
\cline { 2 - 3 } Variable & $\begin{array}{c}\text { Littoral } \\
(n=16)\end{array}$ & $\begin{array}{c}\text { Pelagic } \\
(n=13)\end{array}$ & $\begin{array}{c}\text { Littoral } \\
(n=16)\end{array}$ & $\begin{array}{c}\text { Pelagic } \\
(n=13)\end{array}$ \\
\hline Peak COM velocity $\left(\mathrm{m} \mathrm{s}^{-1}\right)$ & $-.2(.38)$ & $.3(.32)$ & $-.3(.20)$ & $.2(.49)$ \\
Peak COM acceleration $\left(\mathrm{m} \mathrm{s}^{-2}\right)$ & $-.2(.36)$ & $-.1(.75)$ & $-.1(.74)$ & $.8(.001)$ \\
Angular velocity $\left({ }^{\circ} \mathrm{s}^{-1}\right)$ & $-.5(.04)$ & $-.6(.03)$ & $-.2(.43)$ & $-.01(.97)$ \\
Distance moved $(\mathrm{m})$ & $-.2(.54)$ & $.2(.46)$ & $.1(.67)$ & $.2(.57)$ \\
\hline
\end{tabular}

Note. Cohen (1988) classified PPMCs of 0.1, 0.3, and 0.5 as representing small, medium, and large effect sizes, respectively. $P$ values are shown in parentheses. Bold type indicates statistical significance. $\mathrm{COM}=$ center of mass.

Our findings are, in part, supported by a "predator-mediated selection" hypothesis: fish from high-predation environments should be exposed to selection pressures that favor fast-start performance (Ghalambor et al. 2004; Domenici et al. 2008; Langerhans 2009; Blob et al. 2010). Fish species that inhabit Lake Waban include pumpkinseed sunfish, largemouth bass, black crappie, chain pickerel, and yellow perch. Of these, largemouth bass are a primary predator of bluegill (Werner et al. 1983) and are often caught while fishing in pelagic areas (D. J. Ellerby and S. P. Gerry, personal observation). In the open water, pelagic fish are also exposed to increased predation from birds. Cormorants frequent the lake, and sunfish can form a majority of the cormorant diet in freshwater habitats (Brugger 1993; Campo et al. 1993; Glahn et al. 1995). The importance of fast-starts for predator evasion may also depend on environmental features. Fast-start performance may be of limited significance for predator evasion in the complex physical environment created by dense vegetation. When exposed to predatory bass in the presence of a simulated aquatic weed bed, littoral bluegill evade predation by maneuvering rapidly through that cover (Chipps et al. 2004). Under these circumstances, agility, which is provided by the high maneuverability of the littoral form (Ellerby and Gerry 2011), may be more important than raw power for predator avoidance. Differences in foraging behavior may also be important factors in shaping acceleration performance. Pelagic bluegill feed on freeswimming zooplankton, and prey capture performance is dictated not just by suction and flow at the mouth but by movement of the whole body (reviewed in Higham 2007). The phenotypic features associated with rapid accelerations for prey capture may not be decoupled from those that favor fast-start performance during predator avoidance.
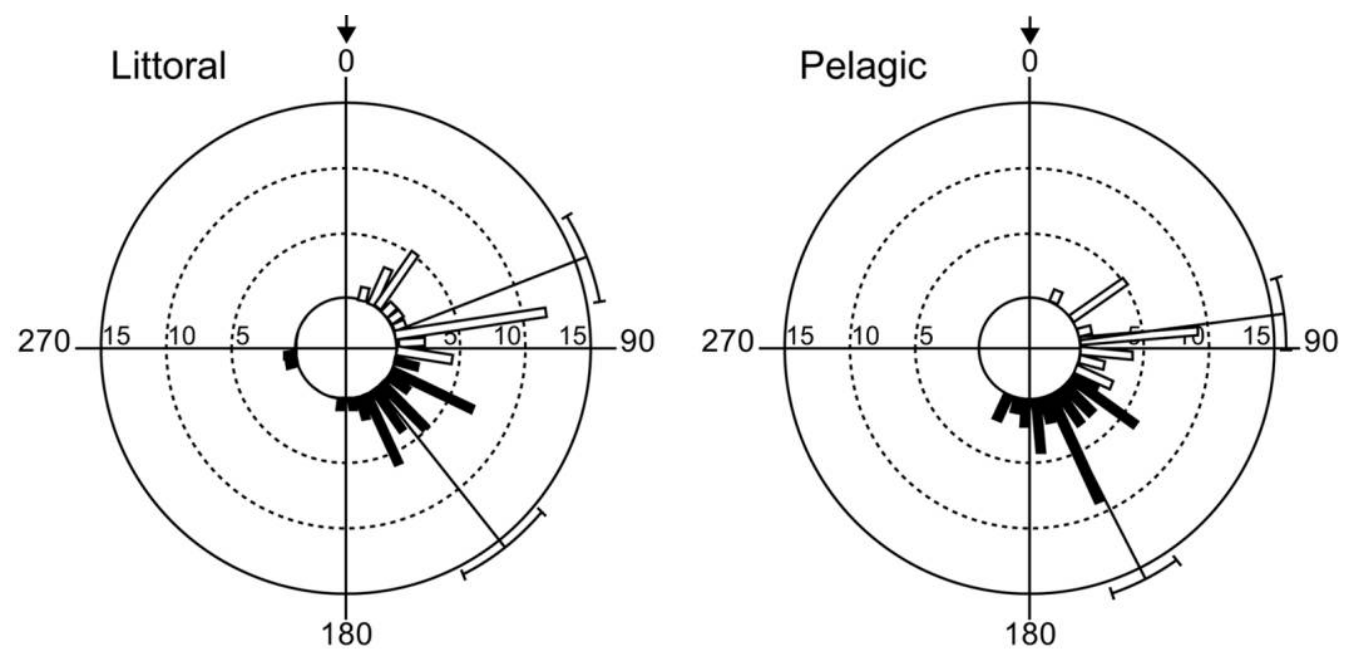

Figure 5. Circular histograms showing the frequency distribution of escape angles for littoral and pelagic fish. Data are pooled across individuals. Radial lines and arcs show the means and circular standard deviations of the escape angle clusters. The stimulus, indicated by an arrow, was delivered directly in front of the fish at $0^{\circ}$. Data from left and right turns are pooled, because the ratio of left : right preference did not differ significantly from $1: 1$, and no significant difference was detected by the angular distributions of left and right turns. The plots therefore show the magnitude of the change in trajectory, not direction. Littoral clusters were at $68.8^{\circ} \pm 23.6^{\circ}$ (32) and $141.1^{\circ} \pm 33.0^{\circ}$ (30), pelagic at $82.5^{\circ} \pm 21.9^{\circ}(34)$ and $153.3^{\circ} \pm 23.8^{\circ}(25)$. Data are shown as the mean \pm circular standard deviation. The total number of observations in each cluster is shown in parentheses. 
The processes that lead to the observed divergence in morphology and performance are of considerable interest. Bluegill construct their nests in the littoral habitat. Larvae and juveniles of both forms hatch and reside among the vegetation until they are large enough to avoid predation by largemouth bass (Mittelbach and Osenberg 1993), at which point the pelagic fish move to the open water. Behavioral and morphological variation is already present in juvenile bluegill by the time they reach 30-70 $\mathrm{mm}$ in length (Chipps et al. 2004). Specific information regarding the genetic factors and developmental processes that underlie divergence in bluegill is lacking, but in other sunfish species, a combination of genetic factors and phenotypic plasticity, largely in response to dietary differences, dictates habitat-specific variation in morphology (Robinson and Wilson 1996; Hegrenes 2001). It is not known whether the scope and nature of the morphological and fast-start performance differences detected in adults are already present in juvenile bluegill. Thus, the fast-start response needs to be compared in juvenile bluegill to determine whether the performance parameters of velocity and acceleration are stereotyped in younger individuals and whether the divergence shown by adults is a consequence of phenotypic divergence later in development or differential selection, in which poorly performing individuals are removed from the pelagic environment by predation.

Despite significant differences in performance between groups, there were no detectable differences in the escape angl $\rightarrow$ distributions (fig. 5). The escape angle is dictated by the timing and magnitude of the myotomal muscle contractions that drive body bending (Foreman and Eaton 1993). The initial C-benc $\rightarrow$ is primarily generated under the control of paired reticulospinal Mauthner neurons and associated command neurons (reviewed in Eaton et al. 2001; Korn and Faber 2005). The antagonisti $\rightarrow$ phase 2 contraction is likely under the control of a second group of neurons (Foreman and Eaton 1993). Neural activity in both groups therefore contributes to forming the final escape angle. Both forms showed a bimodal trajectory distribution (fig. 5 ), with no preference for left versus right turns. The mean values of the peaks are similar in both groups of fish. In practice, this would create a pattern of response with four peaks within the $360^{\circ}$ distribution. Other fish species show a similar bimoda $\rightarrow$ angle magnitude distribution, with escape most successful from $150^{\circ}$ to $180^{\circ}$ (Walker et al. 2005). This bimodal distribution is thought to either maximize the distance between the fish anc $\rightarrow$ its predator or allow for sensory tracking of the predator before a repeat attack (Domenici et al. 2011). The fish do not adop a "protean" response pattern (Driver and Humphries 1988), in which the escape trajectory is random and completely unpredictable (reviewed in Domenici et al. 2011), but the breadtr $\rightarrow$ of the clusters creates considerable variation, with low predictability for the final trajectory. The lack of variation between pelagic and littoral bluegill suggests that the underlying neural control of the behavior does not differ but that the performance difference lies in the effectiveness with which the movements generated by the underlying neural activity are translated into effective thrust production.

In conclusion, greater fast-start performance has been shown in pelagic bluegill living in an open-water environment. This was contrary to initial predictions based on body shape. Faststart performance can be directly linked to organismal fitness, because fish that exhibit fast-starts decrease their risk of predation and may increase their prey capture. Although littoral bluegill show decreased fast-start performance, they are able to maneuver efficiently through the vegetation, which may be more important for evading predators in a complex environment. Future studies of juvenile bluegill are needed to determine whether the divergence shown in fast-start performance is present early in development or whether it arises from habitat-specific environmental cues and/or differential selection. Additionally, integrative studies of internal morphology and physiology are needed to fully reveal the interplay between phenotypic and performance variation.

\section{Acknowledgments}

This research was funded by the National Science Foundation (0715937; D.J.E.) and the Wellesley College Amabel Boyce James Fund for Summer Research in the Sciences (A.R.).

\section{Literature Cited}

Adolph S.C. and T. Pickering. 2008. Estimating maximum performance: effects of intraindividual variation. J Exp Biol 211: 1336-1343.

Bhagat Y., M.G. Fox, and M.T. Ferreira. 2011. Trophic polymorphism in introduced pumpkinseed (Lepomis gibbosus) inhabiting Iberian reservoirs. Environ Biol Fish 91:203-217.

Blake R.W. 2004. Fish functional design and swimming performance. J Fish Biol 65:1193-1222.

Blob R.W., S.M. Kawano, K.M. Moody, W.C. Bridges, T. Maie, M.B. Ptacek, M.W. Julius, and H.L. Schoenfuss. 2010. Morphological selection and the evaluation of potential tradeoffs between escape from predators and the climbing of waterfalls in the Hawaiian stream goby Sicyopterus stimpsoni. Integr Comp Biol 50:1185-1199.

Bolnick D.I. and O.L. Lau. 2008. Predictable patterns of disruptive selection in stickleback in postglacial lakes. Am Nat 172:1-11.

Brugger K.E. 1993. Digestibility of three fish species by doublecrested cormorants. Condor 95:25-32.

Campo J.T., B.C. Thompson, J.C. Barron, R.C. Telfari, P. Durocher, and S. Gutreuter. 1993. Diet of double-crested cormorants wintering in Texas. J Field Ornithol 64:135-144.

Chipps S.R., J.A. Dunbar, and D.H. Wahl. 2004. Phenotypic variation and vulnerability to predation in juvenile bluegill sunfish Lepomis macrochirus. Oecologia 138:32-38.

Cohen J. 1988. Statistical power analysis for the behavioral sciences. 2nd ed. Ehrlbaum, Hillsdale, NJ.

Cooper H.M. and L.V. Hedges. 1994. The handbook of research synthesis. Russell Sage Foundation, New York.

Domenici P. 2003. Habitat, body design and the swimming performance of a fish. Pp. 137-160 in V.L. Bels, J.-P. Gasc, 
and A. Casinos, eds. Vertebrate biomechanics and evolution. BIOS Scientific, Oxford.

$\rightarrow$ Domenici P., J.M. Blagburn, and J.P. Bacon. 2011. Animal es $\rightarrow$ capology. I. Theoretical issues and emerging trends in escape trajectories. J Exp Biol 214:2463-2473.

Domenici P. and R.W. Blake. 1997. The kinematics and performance of fish fast-start swimming. J Exp Biol 200:1165-1178.

$\rightarrow$ Domenici P., H. Turesson, J. Brodersen, and C. Brönmark. 2008. Predator-induced morphology enhances escape locomotion in crucian carp. Proc R Soc B 275:195-201.

Driver P.M. and N. Humphries. 1988. Protean behavior: the biology of unpredictability. Oxford University Press, Oxford.

$\rightarrow$ Eaton R.C., R.K. Lee, and K. Foreman. 2001. The Mauthner cell and other identified neurons of the brainstem escap $\rightarrow$ network of fish. Prog Neurobiol 63:467-485.

$\rightarrow$ Ehlinger T.J. 1990. Habitat choice and phenotype-limited feeding efficiency in bluegill: individual differences and trophic polymorphism. Ecology 71:886-896.

$\rightarrow$ Ehlinger T.J. and D.S. Wilson. 1988. Complex foraging polymorphism in bluegill sunfish. Proc Natl Acad Sci USA $85 \rightarrow$ 1878-1882.

$\rightarrow$ Ellerby D.J. and S.P. Gerry. 2011. Sympatric divergence and performance trade-offs of bluegill ecomorphs. Evol Biol 38 422-433.

Foreman M.B. and R.C. Eaton. 1993. The direction change concept for reticulospinal control of goldfish escape. J Neu $\rightarrow$ rosci 13:4104-4113.

$\rightarrow$ Garland T., Jr., A.F. Bennett, and E.L. Rezende. 2005. Phylogenetic approaches in comparative physiology. J Exp Biol 208:3015-3035.

$\rightarrow$ Gerry S.P., J. Wang, and D.J. Ellerby. 2011. A new approach to quantifying morphological variation in bluegill Lepomis macrochirus. J Fish Biol 78:1023-1034.

$\rightarrow$ Ghalambor C.K., D.N. Reznick, and J.A. Walker. 2004. Constraints on adaptive evolution: the functional trade-off between reproduction and fast-start swimming performance in th $\rightarrow$ Trinidadian guppy (Poeciliareticulata). Am Nat 164:38-50.

$\rightarrow$ Glahn J.F., P.J. Dixson, G.A. Littauer, and R.B. McCoy. $1995 \rightarrow$ Food habits of double-crested cormorants wintering in the delta region of the Mississippi. Colon Waterbirds 18:158-167.

$\rightarrow$ Grice J.W. 2001. Computing and evaluating factor scores. Psychol Methods 6:430-450.

$\rightarrow$ Hegrenes S. 2001. Diet-induced phenotypic plasticity of feeding morphology in the orangespotted sunfish, Lepomishumilis. Ecol Fresh Fish 10:35-42.

$\rightarrow$ Higham T.E. 2007. The integration of locomotion and prey capture in vertebrates: morphology, behavior, and performance. Integr Comp Biol 47:82-95.

Jastrebski C.J. and B.W. Robinson. 2004. Natural selection anc $\rightarrow$ the evolution of replicated trophic polymorphisms in pumpkinseed sunfish (Lepomis gibbosus). Evol Ecol Res 6:285-305.

Koehler A.B. and E.S. Murphree. 1988. A comparison of th $\rightarrow$ Akaike and Schwarz criteria for model selection. J R Stat Soc C 37:187-195.

$\rightarrow$ Korn H. and D.S. Faber. 2005. The Mauthner cell half a century later: aneurobiological model for decision-making? Neuron 47:13-28.

Langerhans R.B. 2009. Trade-off between steady and unsteady swimming underlies predator-driven divergence in Gambusia affinis. J Evol Biol 22:1057-1075.

Langerhans R.B. and D.N. Reznick. 2010. Ecology and evolution of swimming performance in fishes: predicting evolution with biomechanics. Pp. 200-248 in P. Domenici and B.G. Kapoor, eds. Fish locomotion: an etho-ecological perspective. Science, Enfield, NH.

Mittelbach G.G. 1981. Foraging efficiency and body size: a study of optimal diet and habitat use by bluegills. Ecology 62:13701386.

$\rightarrow$ Mittelbach G.G. and C.W. Osenberg. 1993. Stage-structured interactions in bluegill: consequences of adult resource variation. Ecology 74:2381-2394.

Parsons K.J. and B.W. Robinson. 2006. Replicated evolution of integrated plastic responses during early adaptive divergence. Evolution 60:801-813.

$\rightarrow$ 2007. Foraging performance of diet-induced morphotypes in pumpkinseed sunfish (Lepomis gibbosus) favours resource polymorphism. J Evol Biol 20:673-684.

$\rightarrow$ Robinson B.W. 2000. Trade offs in habitat-specific foraging efficiency and the nascent adaptive divergence of sticklebacks in lakes. Behaviour 137:865-888.

$\rightarrow$ Robinson B.W. and D.S. Wilson. 1996. Genetic variation and phenotypic plasticity in a trophically polymorphic population of pumpkinseed sunfish (Lepomis gibbosus). Evol Ecol 10:631-652.

$\rightarrow$ Robinson B.W., D.S Wilson, and G.O. Shea. 1996. Trade-offs of ecological specialization: an intraspecific comparison of pumpkinseed sunfish phenotypes. Ecology 77:170-178.

$\rightarrow$ Ryan T.A. 1960. Signficance tests for multiple comparison of proportions, variances and other statistics. Psych Bull 57: 318-328.

$\rightarrow$ Schluter D. 1994. Experimental evidence that competition promotes divergence in adaptive radiation. Science 266:798-800.

$\rightarrow$ Schwarz G. 1978. Estimating the dimension of a model. Ann Stat 6:461-464.

Sneek J.M. 1984. Modelling procedures for univariate time series. Free University, Amsterdam.

$\rightarrow$ Svanbäck R. and P. Eklöv. 2003. Morphology dependent foraging efficiency in perch: a trade-off for ecological specialization? Oikos 102:273-284.

$\rightarrow$ Taylor E.B. and J.D. McPhail. 1985. Variation in burst and prolonged swimming performance among British Columbia populations of Coho salmon, Oncorhyncus kisutch. Can J Fish Aquat Sci 42:2029-2033.

- 1986. Prolonged and burst swimming in anadromous and freshwater threespine stickleback, Gasterosteus aculeatus. Can J Zool 64:416-420.

Tytell E.D. and G.V. Lauder. 2008. Hydrodynamics of the escape response in bluegill sunfish, Lepomis macrochirus. J Exp Biol 211:3359-3369.

Wakeling J.M. 2006. Fast-start mechanics. Pp. 333-368 in R.E. 
Shadwick and G.V. Lauder, eds. Fish biomechanics. Vol. 23. Webb P.W. 1978. Fast-start performance and body form in Fish physiology. Academic Press, San Diego, CA. seven species of teleost fish. J Exp Biol 74:211-226.

$\rightarrow$ Walker J.A. 1997. Ecological morphology of lacustrine three $\rightarrow$ spine stickleback Gasterosteusaculeatus L. (Gasterosteidae) body shape. Biol J Linn Soc 61:3-50.

- 1998. Estimating velocities and accelerations of animal locomotion: a simulation experiment comparing numerica $\rightarrow$ Werner E.E., G.G. Mittelbach, D.J. Hall, and J.F. Gilliam. 1983. differentiation algorithms. J Exp Biol 201:981-985. Experimental tests of optimal habitat use in fish: the role of

$\rightarrow$ Walker J.A., C.K. Ghalambor, O.L. Griset, D. McKenney, and relative habitat profitability. Ecology 64:1525-1539.

D.N. Reznick. 2005. Do faster starts increase the probabilit $\rightarrow$ Yonekura R., K. Nakai, and M. Yuma. 2002. Trophic polymorof evading predators? Funct Ecol 19:808-815. phism in introduced bluegill in Japan. Ecol Res 17:49-57. 